\title{
CONTROLE DE TIRIRICA COM SULFENTRAZONE E DICLOSULAM E VIABILIDADE DE TUBÉRCULOS EM DIFERENTES PROFUNDIDADES DE SOLO $\left({ }^{1}\right)$
}

\author{
DAGOBERTO MARTINS $\left({ }^{2 *}\right)$; MARIO SERGIO TOMAZELA $\left({ }^{2}\right)$; DOMINGOS VANESSA DAVID $\left({ }^{3}\right)$; \\ CIBELE CHALITA MARTINS $\left({ }^{2}\right)$
}

\begin{abstract}
RESUMO
O objetivo deste estudo foi avaliar a eficiência dos herbicidas sulfentrazone e diclosulam no controle de tiririca Cyperus rotundus L. na cultura da cana-de-açúcar e determinar a viabilidade dos tubérculos. O delineamento experimental utilizado foi em blocos inteiramente casualizados, com quatro repetições onde foram dispostos os tratamentos referentes às cinco doses de diclosulam $\left(75,100,150,200 \mathrm{e}^{2} 20 \mathrm{~g} \mathrm{ha}^{-1}\right)$, duas doses de sulfentrazone (800 e $1.000 \mathrm{~g} \mathrm{ha}^{-1}$ ), além de duas testemunhas, uma capinada e outra sem capina. Aos 110 dias após a aplicação dos herbicidas, retiraram-se três subamostras de solo nas profundidades de 0 a 10 e 10 a $20 \mathrm{~cm}$, tanto do sulco de plantio como do camalhão. Os tubérculos de tiririca das amostras de solo foram colocados para germinar em casa-de-vegetação a fim de avaliar sua viabilidade. Após 45 dias da aplicação, os herbicidas propiciaram controles considerados de regular a excelente $(75,8$ a $96,0 \%)$. No sulco de plantio, todas as doses de ambos os herbicidas reduziram o número de tubérculos dormentes nas duas profundidades estudadas. No camalhão, as doses de diclosulam de 100 e $150 \mathrm{~g} \mathrm{ha}^{-1}$ aumentaram a mortalidade de tubérculos em 38\% e 63\%, respectivamente. As doses intermediárias de diclosulam (150 $\mathrm{g} \mathrm{ha}^{-1}$ ) propiciaram alta mortalidade de tubérculos e doses elevadas (250 $\left.\mathrm{g} \mathrm{ha}^{-1}\right)$ induziram à dormência no sulco de plantio.
\end{abstract}

Palavras-chave: Cyperus rotundus L., cana-de-açúcar, herbicida, tubérculo.

\section{ABSTRACT \\ PURPLE NUTSEDGE CONTROL WITH SULFENTRAZONE AND DICLOSULAM AND TUBERS VIABILITY IN DIFFERENT SOIL DEPTHS}

This study aimed to evaluate purple nutsedge (Cyperus rotundus L.) control using diclosulam and sulfentrazone herbicides, and to determine tubers viability in different soil depths after the herbicides application on the sugarcane crop. The trial was carried out in a randomized complete block design, with four replications, where the treatments were five doses at diclosulam (75, 100, 150, 200 and $250 \mathrm{~g}^{-1}$ ), two doses at sulfentrazone ( 800 and $1,000 \mathrm{~g} \mathrm{ha}^{-1}$ ) and weady and no weedy control. At 110 days after herbicide application, soil subsamples collected from the row and ridge planting at depth $(0-10$ and $10-20 \mathrm{~cm})$. The purple nutsedge tubers were found in soil sample were put to germination at greenhouse to evaluate their viability. After 45 days at application, herbicides showed controls that were considered regular to excellent $(75.8 \%$ to $96.0 \%)$. In the planting row, all the herbicides doses analyzed reduced the number of dormant tubers at two depths studied in relation to control. In the ridge planting, diclosulam at 100 and $150 \mathrm{~g} \mathrm{ha}^{-1}$ increased the mortality of tubers in 38 and $63 \%$, respectively. The herbicide diclosulam at $150 \mathrm{~g} \mathrm{ha}^{-1} \mathrm{showed}$ high mortality of tubers and at $250 \mathrm{~g} \mathrm{ha}^{-1}$ induced at the dormancy in the planting row.

Key words: Cyperus rotundus, sugarcane, herbicide, tuber.

$\left({ }^{1}\right)$ Recebido para publicação em 11de setembro de 2006 e aceito em 7 de janeiro 2009.

( $\left.{ }^{2}\right)$ Departamento de Produção Vegetal, FCA-UNESP, Caixa Postal 237, 18603-970 Botucatu (SP), Brasil. E-mail: dmartins@fca.unesp.br $\left({ }^{*}\right)$ Autor correspondente.

${ }^{(3)}$ Departamento de Agricultura, Escola Agrotécnica Federal de Araguatins (EAFA), Tocantins (TO). 


\section{INTRODUÇÃO}

No Brasil, estima-se que um milhão de hectares de cana-de-açúcar esteja infestado com Cyperus rotundus L. (tiririca), de um total de 6,2 milhões de hectares, posto que em áreas com alta infestação esta espécie pode causar perdas na produção entre $65 \%$ e $75 \%$, caso não seja adotada nenhuma medida de controle (TAVARES e Hora, 2006; FRANCO et al., 2006).

A tiririca, uma das principais plantas infestantes, competindo com 52 plantas cultivadas em 92 países (Holm et al., 1977), é considerada uma das plantas mais daninhas do mundo por sua ampla distribuição, capacidade de competição, agressividade e pela dificuldade em ser controlada ou erradicada (Stoller e sweet, 1987; Kissmann e Groth, 1997; LORENZI, 2000).

C. rotundus é uma espécie perene que produz poucas sementes viáveis. O principal meio de disseminação consiste na produção de tubérculos e de bulbos basais. A dilatação dos rizomas que forma a base dos ramos aéreos (folhas e hastes florais) é denominada de bulbo basal. Os bulbos basais e tubérculos se fundem para formar propágulos, no entanto, bulbos basais são diferentes morfologicamente (Stoller e SWEET, 1987; Wills, 1987; MeLLo et al., 2003).

Mello et al. (2003) observaram na tiririca dominância apical e dormência de gemas. A dominância apical foi constatada individualmente nos tubérculos, cuja brotação surge inicialmente na gema apical, enquanto as outras gemas permanecem dormentes. No entanto, estas gemas dormentes, podem brotar quando ocorre a morte da parte aérea da planta.

A disseminação dessa espécie pode ser limitada pela sua intolerância à baixa temperatura e à seca, não se desenvolvendo também em áreas muito sombreadas ou com alto nível de salinidade (ОкоLLI et al., 1997; LORENZI, 2000). Contudo, esta espécie é uma planta $\mathrm{C}_{4}$, com sensibilidade ao sombreamento, e em condições favoráveis ao crescimento são eficientes na conversão de massa seca em tubérculos, que corresponde de $44 \%$ a $50 \%$ massa seca total da planta (STOLLER e SWEET, 1987).

Em condições ambientais favoráveis (temperatura elevada e intensa luminosidade), seu estabelecimento pode ser mais rápido devido ao intenso crescimento vegetativo e à produção de tubérculos, sendo estes os principais fatores que definem a habilidade competitiva com as culturas. Os tubérculos atuam como as principais unidades de dispersão, permanecendo dormentes no solo por longos períodos. Os diferentes "graus" de dormência dos tubérculos causam emergência irregular e, assim, contribui para a manutenção dessa espécie daninha no solo (Miles et al., 1996). Atualmente, o controle químico é o método mais eficaz no controle de tiririca e, entre os herbicidas aplicados em pré-emergência, o sulfentrazone e o diclosulam são considerados os mais eficientes.

O herbicida sulfentrazone é recomendado para a aplicação em diversas culturas dentre elas, a cana-de-açúcar. LANGBECK et. al (2004) avaliaram o efeito de sulfentrazone, aplicado em préemergência, sobre o desenvolvimento da parte aérea e subterrânea da tiririca. Relataram que houve redução acentuada na formação das suas estruturas subterrâneas e aéreas, com a aplicação de 0,6 a 0,8 $\mathrm{kg} \mathrm{ha}{ }^{-1}$, porém não eliminou a viabilidade dos tubérculos, que ficaram dormentes $(15,38 \%$ e $7,7 \%$ de tubérculos viáveis, respectivamente). Este resultado comprova que o produto não elimina os tubérculos de tiririca, o que possibilita a ocorrência de reinfestação.

De forma oposta, a utilização da dose de 0,9 $\mathrm{kg} \mathrm{ha}^{-1}$ de sulfentrazone, em pré-emergência, proporcionou baixa eficiência de controle sobre as plantas de C. rotundus, com controle visual inferior a 40\% (CARneiro et al, 2006). TERRA (2003) observou excelente seletividade à cultura de cana-de-açúcar e níveis de controle de 80 a 98,9\% entre as doses de 0,8 a $1,0 \mathrm{~kg} \mathrm{ha}^{-1}$.

O herbicida diclosulam é aplicado para o controle de plantas daninhas na cultura da soja (BARNES et al. 1998 e BAILEY et al. 1999 a, 1999 b;). TERRA (2003) avaliou a seletividade de quinze cultivares de cana-de-açúcar e, independente da época de aplicação e ciclo da cultura, em todos os genótipos houve seletividade a este herbicida.

Outro aspecto que deve ser considerado no manejo de plantas daninhas, na cultura da cana-deaçúcar, é o tipo de colheita a ser realizado: cana "queimada" ou cana "crua". O revolvimento do solo pode separar os tubérculos dos rizomas, quebrando a dormência apical e favorecendo a brotação ou mesmo causando sua morte quando efetuado em época seca. Portanto, pode ser considerada como uma prática viável de controle quando associado ao uso de herbicidas. Na colheita de cana "crua", somente a palhada como cobertura morta não seria suficiente como fator de supressão da emergência de C. rotundus (Stoller e Sweet, 1987; Silva, et al., 2003), mesmo sendo plantas de ciclo $C_{4}$, sensíveis ao sombreamento.

O presente trabalho teve como objetivo avaliar o controle de plantas de C. rotundus pelos herbicidas 
diclosulam e sulfentrazone e determinar a viabilidade dos tubérculos presentes em diferentes profundidades no sulco de plantio e camalhão.

\section{MATERIAL E MÉTODOS}

O experimento foi instalado e desenvolvido, no campo, no município de Jaú (SP), em um Latossolo Vermelho-Escuro, sendo a área pertencente à usina Diamante. A cultivar de cana-de-açúcar utilizada foi a SP-79 2233, sendo plantada no sistema convencional em 19/4/97. As características químicas do solo na camada de 0 a $25 \mathrm{~cm}$ eram: $\mathrm{pH} 4,9$; matéria orgânica $1,0 \mathrm{~g} \mathrm{dm}^{-3}$; P em resina $15 \mathrm{~g} \mathrm{dm}^{-3} ; \mathrm{K} 1,4 \mathrm{cmol}_{\mathrm{c}} \mathrm{dm}^{-3}$; Ca $3,0 \mathrm{cmol}_{\mathrm{c}} \mathrm{dm}^{-3} ; \mathrm{Mg} \mathrm{0,7} \mathrm{cmol}_{\mathrm{c}} \mathrm{dm}^{-3} ; \mathrm{H}+\mathrm{Al} \mathrm{2,9} \mathrm{cmol}_{\mathrm{C}}$ $\mathrm{dm}^{-3}$; CTC $8 \mathrm{cmol}_{\mathrm{c}} \mathrm{dm}^{-3}$; SB 5,1 $\mathrm{cmol}_{\mathrm{c}} \mathrm{dm}^{-3}$; V $64 \%$.

Os tratamentos consistiram de cinco doses de diclosulam (75, 100, 150, 200 e $250 \mathrm{~g} \mathrm{ha}^{-1}$ ) e duas doses de sulfentrazone (800 e 1000 $\left.\mathrm{g} \mathrm{ha}^{-1}\right)$, além de duas testemunhas, uma capinada e outra sem capina. Em todos os tratamentos químicos, foi adicionado Aterbane a $0,05 \% \mathrm{v} / \mathrm{v}$. Os dados pluviométricos de abril, maio, junho, julho e agosto foram, respectivamente, de 0, 109,6, 159,8, 32,2 e $0 \mathrm{~mm}$, obtidos na estação meteorológica da usina. O início das chuvas ocorreu apenas 21 dias após a implantação do experimento.

O delineamento experimental utilizado foi em blocos inteiramente casualizados, com quatro repetições. Os tratamentos foram dispostos em parcelas constituídas por cinco linhas de $10 \mathrm{~m}$ de comprimento, perfazendo uma área de $75 \mathrm{~m}^{2}$. A profundidade do sulco de plantio foi de 20 a $25 \mathrm{~cm}$.

O equipamento utilizado na aplicação dos herbicidas foi um pulverizador costal, à pressão constante mantida pelo $\mathrm{CO}_{2}$ comprimido a 1,97 $\mathrm{kgf} \mathrm{cm}{ }^{-2}$, equipado com barra de aplicação munida de pontas Teejet $80.02 \times R$, com consumo de calda a $181 \mathrm{~L} \mathrm{ha}^{-1}$. A aplicação foi realizada em préemergência das plantas daninhas. Na data da aplicação, a temperatura era de $36{ }^{\circ} \mathrm{C}$ e $45 \%$ de umidade relativa, e a velocidade do vento variou de 0,5 a $2,0 \mathrm{~m} \mathrm{~s}^{-1}$.

Antes da aplicação dos herbicidas, foram realizadas 15 amostragens pontuais prévias na área experimental tanto no sulco de plantio como no camalhão, nas profundidades de $0-10 \mathrm{~cm}$ e $10-20 \mathrm{~cm}$, respectivamente. Para a coleta da amostra de solo com tubérculos utilizou-se uma cavadeira com diâmetro de $15 \mathrm{~cm}$. Aos 110 dias após a aplicação dos herbicidas, em cada parcela, retiram-se três subamostras por profundidade tanto no sulco de plantio como no camalhão.
As variáveis analisadas foram: porcentagem de controle da tiririca aos 30, 45, 60, 90 e 110 dias após a aplicação dos herbicidas (DAAH), sintomas de intoxicação às plantas de cana-de-açúcar aos 15, 30, 45 e $60 \mathrm{DAAH}$, por meio de uma escala percentual onde a ausência de injúria correspondeu ao valor zero e à morte da planta, 100. Aos $110 \mathrm{DAAH}$, o banco de tubérculos foi avaliado em casa de vegetação quando foram classificados como germinados, dormentes ou mortos. A viabilidade dos tubérculos não germinados foi avaliada empregando-se o teste de tetrazólio. Os tubérculos foram cortados no sentido longitudinal, embebidos em solução de $0,1 \%$ de sal de tetrazólio, colocado em BOD a $30{ }^{\circ} \mathrm{C}$ por 1,5 horas, sendo considerados viáveis e dormentes os tubérculos que se coloriram de rosa no fim do período.

Os dados foram submetidos à análise de variância pelo teste $\mathrm{F}$ sendo as médias comparadas pelo teste de Tukey a $5 \%$ de probabilidade.

\section{RESULTADOS E DISCUSSÃO}

Observou-se no levantamento prévio, em média, no sulco de plantio e na profundidade de 0 a $10 \mathrm{~cm}$ a quantidade de 541 tubérculos $\mathrm{m}^{-2}$, sendo $52 \%$ viáveis (281). Na profundidade de 10 a $20 \mathrm{~cm}$ foram observados 414 tubérculos $\mathrm{m}^{-2}$, sendo $69 \%$ viáveis (286). No camalhão, observou-se na profundidade de 0 a $10 \mathrm{~cm}, 562$ tubérculos $\mathrm{m}^{-2}$, sendo $60 \%$ viáveis (337) e, na profundidade de 10 a $20 \mathrm{~cm}, 397$ tubérculos $\mathrm{m}^{-2}$, sendo $65 \%$ viáveis (258). Consideraram-se como tubérculos viáveis os que germinaram, bem como os dormentes que responderam ao teste de tetrazólio.

Ambos os herbicidas testados, independentemente das doses aplicadas, causaram injúrias às plantas de cana-de-açúcar (Tabela 1). Aos $15 \mathrm{DAAH}$, que correspondeu ao início da brotação das plantas, não foi observado nenhum efeito tóxico. Este fato pode estar relacionado à baixa precipitação pluvial no período, pois as primeiras chuvas ocorreram apenas aos 21 DAAH. Aos 30 DAAH, nas parcelas tratadas com sulfentrazone, observaram-se efeitos fitotóxicos considerados leves. Entretanto, aos 45 DAAH, em todos os tratamentos com ambos os herbicidas, verificaram-se sintomas leves de intoxicação (Tabela 1). Aos 60 DAAH não foram mais observados visualmente efeitos tóxicos dos herbicidas nas plantas de cana-de-açúcar.

Com sulfentrazone, os sintomas eram manchas elípticas de coloração avermelhada, medindo aproximadamente $1 \mathrm{~cm}$ de comprimento por $0,5 \mathrm{~cm}$ de diâmetro, dispostas no limbo das folhas inferiores. 
Tabela 1. Porcentagem de fitointoxicação de plantas de cana-de-açúcar (variedade SP 79 2233) tratadas com diclosulam e sulfentrazone. Jaú (SP)

\begin{tabular}{lccccc}
\hline \multirow{2}{*}{ Tratamentos } & Dose & \multicolumn{4}{c}{ Fitointoxicação (DAA) } \\
\cline { 2 - 5 } & $\mathrm{g} \mathrm{ha}^{-1}$ & 15 & 30 & 45 & 60 \\
\cline { 2 - 5 } 1. Diclosulam & 75 & 0,0 & 0,0 & 1,5 & 0,0 \\
2. Diclosulam & 100 & 0,0 & 0,0 & 0,8 & 0,0 \\
3. Diclosulam & 150 & 0,0 & 0,0 & 1,5 & 0,0 \\
4. Diclosulam & 200 & 0,0 & 0,0 & 2,5 & 0,0 \\
5. Diclosulam & 250 & 0,0 & 0,0 & 2,3 & 0,0 \\
6. Sulfentrazone & 800 & 0,0 & 1,8 & 2,0 & 0,0 \\
7. Sulfentrazone & 1.000 & 0,0 & 2,0 & 2,8 & 0,0 \\
8. Testemunha capinada & - & 0,0 & 0,0 & 0,0 & 0,0 \\
\hline
\end{tabular}

Nas plantas tratadas com diclosulam, observaram-se manchas cloróticas, medindo aproximadamente 1,5 a $2,0 \mathrm{~cm}$ de comprimento, transversalmente no limbo das folhas inferiores.

DURIGAN et al. (2004) observaram resultados semelhantes de intoxicação em plantas de cana-deaçúcar tratadas com $700 \mathrm{~g} \mathrm{ha}^{-1}$ de sulfentrazone, com e sem cobertura de palha da cultura, com médias de notas variando de $1,2 \%$ a $1,8 \%$, sendo reduzidos gradualmente também até a $60 \mathrm{DAAH}$. A seletividade do sulfentrazone e do diclosulam à cultura de canade-açúcar foi constatada também por TERRA (2003), o que corrobora com os resultados deste trabalho.

Na tabela 2, são apresentados os percentuais de controle de $C$. rotundus nas diferentes épocas de avaliação. Aos 30 DAAH, apenas nas duas maiores doses de diclosulam (200 e $250 \mathrm{~g} \mathrm{ha}^{-1}$ ) observaram-se controles considerados satisfatórios. Em ambas as doses de sulfentrazone (800 e $1.000 \mathrm{~g} \mathrm{ha}^{-1}$ ) os controles variaram de bom a excelente. Ressalta-se que, talvez, o efeito supressor do diclosulam sobre as plantas de tiririca seja mais dependente da umidade do solo do que o sulfentrazone, uma vez que, as primeiras chuvas ocorreram na área experimental apenas aos $21 \mathrm{DAAH}$. Assim, tal fato pode ter influenciado em maior grau a eficiência de controle do diclosulam do que a do sulfentrazone. Os resultados do sulfentrazone, ora observados, corroboram com os constatados por DuRIGAN et al. (2004), os quais verificaram que a dose de $800 \mathrm{~g} \mathrm{ha}^{-1}$ aplicada em préemergência, foi eficaz na redução do número de manifestações epígeas em 96,9 \%, aos 31 DAAH.

Aos 45 DAAH, em todos os tratamentos testados verificaram-se incrementos no controle da espécie daninha, exceto quando aplicado 75 e 150 $\mathrm{g} \mathrm{ha}^{-1}$ de diclosulam, visto que, em todos os demais tratamentos os controles variaram de bom a excelente.
Aos 60 DAAH, verificaram-se incrementos no controle das plantas de $C$. rotundus com a utilização das duas maiores doses de diclosulam (200 e $250 \mathrm{~g}$ ha $^{-1}$ ) e a manutenção do controle proporcionado pelas duas doses do sulfentrazone $(94 \%$ e $96 \%)$. Aos 90 DAAH, todos os tratamentos testados comportaramse de forma semelhante ao período anterior de avaliação. No fim das avaliações, aos 110 DAAH, e com o fechamento das entrelinhas da cultura, verificou-se que todos os herbicidas proporcionaram controles que variaram de satisfatórios a excelentes. A menor dose de diclosulam proporcionou $79 \%$ de controle. Nas duas doses superiores a esta (100 e 150 $\mathrm{g} \mathrm{ha}^{-1}$ ) o controle foi considerado bom $(84 \%)$, e nas duas doses maiores (200 a $250 \mathrm{~g} \mathrm{ha}^{-1}$ ) foram excelentes (95\% e $97 \%$ respectivamente). Ambas as doses de sulfentrazone (800 e $1.000 \mathrm{~g} \mathrm{ha}^{-1}$ ) também propiciaram controles excelentes da planta daninha (95\% e $96 \%$ respectivamente).

LANGBECK et al. (2004) também obtiveram excelentes resultados de controle para C. rotundus com a utilização de sulfentrazone. A eficiência do sulfentrazone no controle desta espécie foi avaliada em diversos trabalhos, sendo ressaltado o potencial supressor deste herbicida por WeHTJE et al. (1997); Werlang et al. (2004) e Negrisoli et al. (2004).

Na tabela 3, estão apresentados o número de tubérculos germinados, dormentes e mortos de amostras coletada nas profundidades de $0-10 \mathrm{~cm}$ e $10-$ $20 \mathrm{~cm}$ no sulco de plantio, aos 110 DAAH. Verificou-se que, independente das profundidades avaliadas, todos os tratamentos químicos propiciaram reduções significativas no número de tubérculos germinados, sendo percentualmente mais expressiva na profundidade de 10 a $20 \mathrm{~cm}$. Nessa profundidade, as doses de diclosulam foram consistentes e eficazes 
na redução da germinação; contudo, observou-se o maior efeito supressor com a aplicação do sulfentrazone (800 $\left.\mathrm{g} \mathrm{ha}^{-1}\right)$, e sua dose maior $(1.000 \mathrm{~g}$ $\mathrm{ha}^{-1}$ ) foi a que proporcionou controle inferior. Tal fato pode ser atribuído, talvez, a variações na quantidade e distribuição de tubérculos no banco de propágulos do solo, variabilidade esta, que geralmente ocorre em estruturas de reprodução vegetativa. No presente estudo, sulfentrazone reduziu o número de tubérculos germinados em $89,7 \%$ e $93,1 \%$ para as doses de 800 e $1.000 \mathrm{~g} \mathrm{ha}^{-1}$ na profundidade de 0 a $10 \mathrm{~cm}$ e em $100 \%$ e $89,7 \%$ de 10 a $20 \mathrm{~cm}$ (Figuras 1 e 2).

Em um estudo no qual se analisou a integração do método mecânico com aplicação de sulfentrazone ou com duas aplicações de glyphosate (DurIGAN, 2006), as reduções nas porcentagens de tubérculos viáveis em $0,018 \mathrm{~m}^{3}$ de solo foram de $72,7 \%$ e $89,4 \%$, respectivamente. Os programas de desinfestação do solo, com o uso de sulfentrazone, isoladamente, apresentaram redução de 57,6\%. Dessa forma, a utilização de implementos mecânicos (arado + grade) na época "seca" potencializou a ação dos herbicidas glyphosate e sulfentrazone nas "águas". Portanto, o controle mecânico na época das águas, deve ser associado ao controle químico, porque no rompimento do rizoma, as gemas adicionais entram em atividade iniciando deste modo a brotação (MELlo et al., 2003).
Todas as doses de ambos os herbicidas estudados reduziram o número de tubérculos dormentes nas duas profundidades estudadas em relação à testemunha, com maior expressividade na dose maior de diclosulam (250 $\mathrm{g} \mathrm{ha}^{-1}$ ) e nas duas doses de sulfentrazone (800 e $1000 \mathrm{~g} \mathrm{ha}^{-1}$ ) na profundidade de 0 a $10 \mathrm{~cm}$ (Figura 1). Na profundidade de 10 a $20 \mathrm{~cm}$, a maior dose do sulfentrazone $\left(1.000 \mathrm{~g} \mathrm{ha}^{-1}\right)$ proporcionou valor superior aos demais tratamentos. DURIGAN et al. (2005) ressaltaram a capacidade de inviabilidade de tubérculos com a aplicação de sulfentrazone na dose de $800 \mathrm{~g} \mathrm{ha}^{-1}$, o que resultou em 78\% inviáveis. Portanto, esses resultados foram semelhantes aos deste trabalho, uma vez que, com esta dose foram observados $70 \%$ de tubérculos mortos nas camadas de 10 a $20 \mathrm{~cm}$, enquanto na camada de 0 a $10 \mathrm{~cm}$, apenas 47,4\% (Figuras 1 e 2).

Novo (2004) constatou na tiririca dominância apical e embora esta seja o principal fator que controla a dormência do tubérculo, a umidade do solo, a luz, o teor de oxigênio e a temperatura influenciam no processo de emissão de brotações. Além disso, uma possível explicação para o problema pode estar relacionada ao tamanho dos tubérculos (HAMMERTON, 1975). Portanto, os tubérculos maiores podem conter mais gemas que os menores; assim, a presença de diferentes tamanhos de tubérculos podem ter contribuído para a variabilidade dos dados.

Tabela 2. Efeito de tratamentos com herbicidas e de suas doses sobre a porcentagem de controle de Cyperus rotundus nas diferentes épocas de avaliação. Jaú (SP)

\begin{tabular}{|c|c|c|c|c|c|c|}
\hline \multirow{2}{*}{ Tratamentos } & \multirow{2}{*}{ Dose } & \multicolumn{5}{|c|}{ Porcentagem de controle (DAA) } \\
\hline & & 30 & 45 & 60 & 90 & 110 \\
\hline & $\mathrm{g} \mathrm{ha}{ }^{-1}$ & & 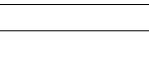 & $\%$ & & \\
\hline 1. Diclosulam & 75 & $55,0 \mathrm{e}$ & $75,8 \mathrm{c}$ & $79,8 \mathrm{c}$ & $76,8 \mathrm{~b}$ & $79,5 \mathrm{~b}$ \\
\hline 2. Diclosulam & 100 & $63,8 \mathrm{~d}$ & $90,8 \mathrm{~b}$ & $79,5 \mathrm{c}$ & $78,8 \mathrm{~b}$ & $84,3 \mathrm{~b}$ \\
\hline 3. Diclosulam & 150 & $25,0 \mathrm{f}$ & $80,5 \mathrm{c}$ & $78,0 \mathrm{c}$ & $77,5 \mathrm{~b}$ & $83,8 \mathrm{~b}$ \\
\hline 4. Diclosulam & 200 & $76,5 \mathrm{c}$ & $91,5 \mathrm{~b}$ & $96,5 \mathrm{ab}$ & 93,5 a & 95,0 a \\
\hline 5. Diclosulam & 250 & $70,0 \mathrm{~cd}$ & $92,5 \mathrm{~b}$ & $97,3 \mathrm{ab}$ & $96,5 \mathrm{a}$ & 97,3 a \\
\hline 6. Sulfentrazone & 800 & $86,8 \mathrm{~b}$ & $93,0 \mathrm{~b}$ & $94,0 \mathrm{~b}$ & 95,8 a & $95,3 \mathrm{a}$ \\
\hline 7. Sulfentrazone & 1.000 & 96,5 a & $96,0 \mathrm{~b}$ & $96,0 \mathrm{ab}$ & 93,3 a & 95,8 a \\
\hline 8. Testemunha capinada & - & $100 \mathrm{a}$ & $100 \mathrm{a}$ & $100 \mathrm{a}$ & $100 \mathrm{a}$ & $100 \mathrm{a}$ \\
\hline F Bloco & - & $0,34^{\mathrm{ns}}$ & $0,79^{\mathrm{ns}}$ & $1,62^{\mathrm{ns}}$ & $0,32^{\mathrm{ns}}$ & $1,47^{\mathrm{ns}}$ \\
\hline F Tratamento & - & $191,3^{* *}$ & $33,5^{* *}$ & $91,3^{* *}$ & $24,8^{* *}$ & $26,0^{* *}$ \\
\hline $\mathrm{CV}(\%)$ & - & 34,8 & 3,1 & 2,2 & 4,3 & 3,3 \\
\hline DMS & - & 34,95 & 6,55 & 4,65 & 9,17 & 7,08 \\
\hline
\end{tabular}

DAA = Dias Após Aplicação.

Adicionou-se aterbane a $0,05 \% \mathrm{v} / \mathrm{v}$ em todos os tratamentos químicos.

ns = Não significativo ao nível de $5 \%$ de probabilidade.

* = significativo ao nível de $1 \%$ de probabilidade pelo teste de Tukey.

Médias seguidas de mesma letra na coluna, não diferem estatisticamente entre si, pelo teste $t(P>0,05)$.

$\mathrm{CV}=$ Coeficiente de variação

DMS = Diferença mínima significativa. 
Tabela 3. Número de tubérculos germinados, dormentes e mortos no sulco de plantio $\left(\mathrm{n} .^{\circ} \mathrm{m}^{2}\right)$, aos 110 dias após a aplicação dos herbicidas, diclosulam e sulfentrazone em diferentes profundidades. Jaú (SP)

\begin{tabular}{|c|c|c|c|c|}
\hline \multirow{2}{*}{ Tratamentos } & \multirow{2}{*}{ Dose } & \multicolumn{3}{|c|}{ Profundidade 0 a $10 \mathrm{~cm}$} \\
\hline & & germinados & dormentes & mortos \\
\hline & $\mathrm{g} \mathrm{ha}^{-1}$ & \multicolumn{3}{|c|}{$\mathrm{n}^{\circ} \mathrm{m}^{-2}$} \\
\hline 1. Diclosulam & 75 & $47,8 \mathrm{c}$ & $79,6 \mathrm{~cd}$ & 72,0 ef \\
\hline 2. Diclosulam & 100 & $31,9 \mathrm{~d}$ & $119,4 \mathrm{~b}$ & $246,8 \mathrm{~b}$ \\
\hline 3. Diclosulam & 150 & $55,7 \mathrm{~b}$ & 87,6 c & 277 a \\
\hline 4. Diclosulam & 200 & $15,9 \mathrm{f}$ & $111,5 \mathrm{~b}$ & $151,4 \mathrm{~d}$ \\
\hline 5. Diclosulam & 250 & $8,0 \mathrm{~g}$ & $71,7 \mathrm{ed}$ & $167,2 \mathrm{c}$ \\
\hline 6. Sulfentrazone & 800 & 23,9 e & $55,7 \mathrm{e}$ & 72,8 ef \\
\hline 7. Sulfentrazone & 1.000 & $15,9 \mathrm{f}$ & $23,9 \mathrm{f}$ & 79,8 e \\
\hline 8. Testemunha no mato & - & 230,9 a & 230,9 a & $64 \mathrm{f}$ \\
\hline F Bloco & & $2,39^{\text {ns }}$ & $1,54^{\mathrm{ns}}$ & $6,47^{\mathrm{ns}}$ \\
\hline F Tratamento & & $1164,5^{* *}$ & $126,5^{* *}$ & $742,9 * *$ \\
\hline $\mathrm{CV}(\%)$ & & 8,9 & 12,5 & 4,9 \\
\hline \multirow[t]{2}{*}{ DMS } & & 6,23 & 16,15 & 14,28 \\
\hline & & \multicolumn{3}{|c|}{ - 0 a $20 \mathrm{~cm}$} \\
\hline 1. Diclosulam & 75 & $9,6 \mathrm{c}$ & $23,9 \mathrm{f}$ & $63,7 \mathrm{c}$ \\
\hline 2. Diclosulam & 100 & $7,7 \mathrm{c}$ & $71,7 \mathrm{c}$ & 135,4 a \\
\hline 3. Diclosulam & 150 & $8,0 \mathrm{c}$ & $23,9 \mathrm{f}$ & 87,6 b \\
\hline 4. Diclosulam & 200 & $7,6 \mathrm{c}$ & $47,7 \mathrm{e}$ & $23,9 \mathrm{f}$ \\
\hline 5. Diclosulam & 250 & $8,0 \mathrm{c}$ & $55,7 \mathrm{~d}$ & $31,9 \mathrm{e}$ \\
\hline 6. Sulfentrazone & 800 & $0,0 \mathrm{~d}$ & $23,9 \mathrm{f}$ & $55,7 \mathrm{~d}$ \\
\hline 7. Sulfentrazone & 1.000 & $23,9 \mathrm{~b}$ & $79,6 \mathrm{~b}$ & $23,9 \mathrm{f}$ \\
\hline 8. Testemunha no mato & - & 87,6 a & 95,5 a & $23,9 \mathrm{f}$ \\
\hline F Bloco & - & $0,22^{\mathrm{ns}}$ & $0,56^{\mathrm{ns}}$ & $2,90^{\mathrm{ns}}$ \\
\hline F Tratamento & - & $504,5^{* *}$ & $138,3^{* *}$ & $435,7^{* *}$ \\
\hline CV (\%) & - & 14,9 & 10 & 7,7 \\
\hline DMS & - & 3,67 & 6,87 & 5,53 \\
\hline
\end{tabular}

test. = testemunha

DAA = Dias Após Aplicação

Adicionou-se aterbane a $0,05 \% \mathrm{v} / \mathrm{v}$ em todos tratamentos químicos.

ns = Não significativo

** = significativo ao nível de $1 \%$ de probabilidade pelo teste F.

Médias seguidas de mesma letra na coluna, não diferem estatisticamente entre si, pelo teste $t(P>0,05)$.

$\mathrm{CV}=$ Coeficiente de variação

DMS = Diferença mínima significativa

LANGBECK et al (2004) confirmaram o potencial de rebrota da espécie, mesmo sendo utilizado o sulfentrazone na dose recomendada em condições de campo $\left(800 \mathrm{~g} \mathrm{ha}^{-1}\right)$. Os pesquisadores observaram, ainda, 7,7\% de tubérculos viáveis com dormência forçada, sendo suficientes para servirem de fonte de reinfestação. No entanto, quando foram aplicados $1.000 \mathrm{~g} \mathrm{ha}^{-1}$ do produto, observou-se mais de $33 \%$ das estruturas viáveis. Esses resultados, às vezes contraditórios, geralmente ocorrem em estudos de banco de propágulos em função da heterogeneidade de infestação, bem como os fatores ambientais e genéticos.
Pereira (1998) relata que embora o índice de germinação de sementes de tiririca seja apenasde $5 \%$ (de um total de 131 milhões de sementes ha-1) ainda assim esta taxa de fecundação cruzada pode ser significativa para garantir a diversidade genética da espécie, bem como não se desconsidere possível taxa de mutações ocorrida entre as populações. Os estudos de Pereira (1998) e Mello et al. (2003) demonstraram grande variabilidade genética dentro da espécie, assim, diferenças de respostas aos herbicidas e doses constatada s na literatura podem ser consideradas normais. 


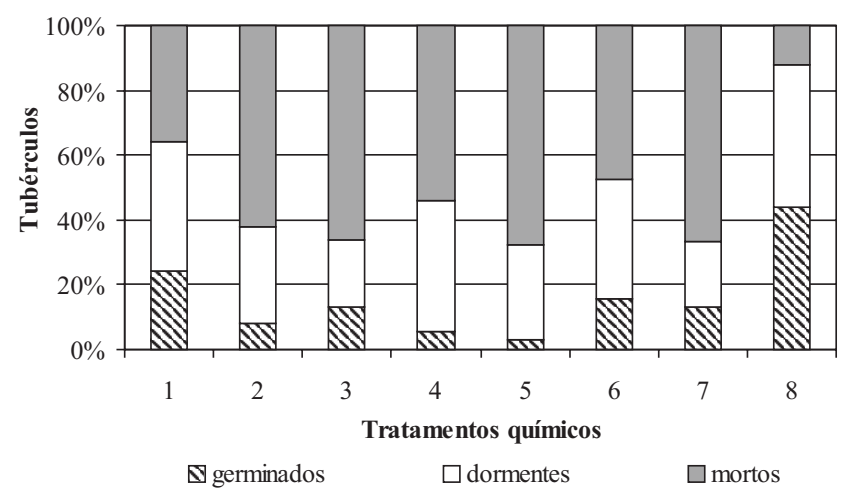

1. diclosulam 75; 2. diclosulam 100; 3. diclosulam 150; 4. diclosulam 200 5. diclosulam $250 ; 6$. sulfentrazone $800 ; 7$. sulfentrazone $1000 \mathrm{~g} \mathrm{ha}^{-1}$

Figura 1. Porcentagem de tubérculos germinados, dormentes e mortos no sulco de 0 a $10 \mathrm{~cm} \mathrm{de}$ profundidade após tratamento com herbicidas em diferentes doses. Jaú (SP).

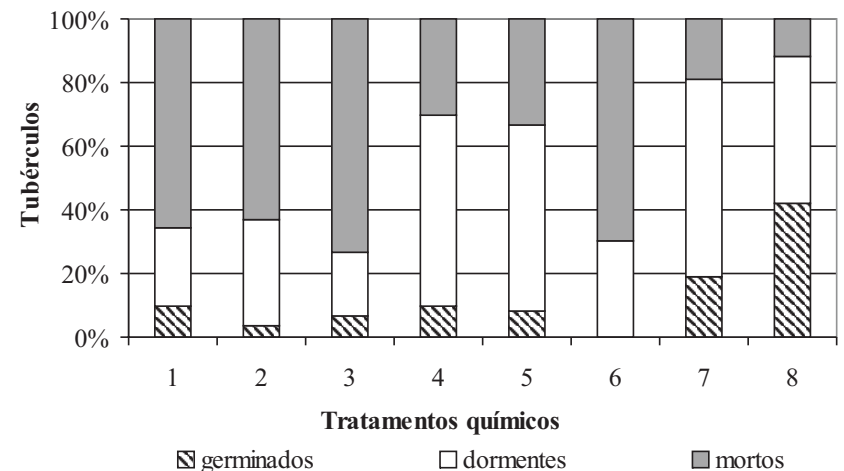

1. diclosulam 75; 2. diclosulam 100; 3. diclosulam 150; 4. diclosulam 200 5. diclosulam $250 ; 6$. sulfentrazone $800 ; 7$. sulfentrazone $1000 \mathrm{~g} \mathrm{ha}^{-1}$

Figura 2. Porcentagem de tubérculos germinados, dormentes e mortos no sulco de 10 a $20 \mathrm{~cm}$ de profundidade após tratamento com herbicidas em diferentes doses. Jaú (SP).

Quanto ao número de tubérculos observados no camalhão (Tabela 4), verificou-se maior redução na germinação em relação ao observado no sulco de plantio. Todos os herbicidas e doses testados, na camada de 0 a 10 $\mathrm{cm}$, proporcionaram reduções significativas no número de tubérculos germinados e na dose de 250 $\mathrm{g} \mathrm{ha}^{-1}$ de diclosulam tiveram germinação nula. Todos os tratamentos foram eficazes na supressão de manifestações epígeas, sendo a dose menor de diclosulam (75 $\mathrm{g} \mathrm{ha}^{-1}$ ) a que proporcionou o resultado menos expressivo.

$\mathrm{Na}$ camada de 10 a $20 \mathrm{~cm}$, houve maior germinação nas parcelas que receberam a dose de 75 $\mathrm{g} \mathrm{ha}^{-1}$, que foi superior à própria testemunha. Contudo, nos demais tratamentos o número de tubérculos germinados foi inferior à testemunha. A reduzida quantidade de tubérculos que germinaram na testemunha pode estar relacionada à dispersão e distribuição desuniforme que geralmente ocorre em plantas com propagação vegetativa (HAMMERTON, 1975; Pereira, 1998).

Observou-se que o herbicida diclosulam, de maneira geral, com exceção da dose de $200 \mathrm{~g} \mathrm{ha}^{-1}$ na camada de 10 a $20 \mathrm{~cm}$, induziu a dormência dos tubérculos, uma vez que foram constatados tubérculos dormentes em maior quantidade nas parcelas tratadas com este herbicida. Ressalta-se que na camada superficial $(0$ a $10 \mathrm{~cm})$ houve maior dormência da testemunha em relação aos tratamentos químicos, sendo mais expressivos do que os resultados constantes da camada de 10 a $20 \mathrm{~cm}$. Este fato pode estar relacionado à maior disponibilidade de produto na camada superficial em relação à camada mais profunda. Outro fator que pode ter influenciado nos resultados refere-se à própria constituição do camalhão, o qual é construído de forma mecânica e artificial. Este fato causa a desestruturação do perfil do solo, pela movimentação dos agregados do solo, o que altera a porosidade natural e condiciona à temperaturas mais elevadas, bem como minimiza a lixiviação, favorecendo assim a maior dormência e morte dos tubérculos.

A provável indução da dormência ocasionada pelo herbicida diclosulam pode ser considerada relativa em termos de controle, uma vez que, o período de permanência da dormência não foi determinado nestas condições estudadas. Portanto, torna-se necessário realizar outros estudos que possibilitem afirmar o período de controle do herbicida, com base no tempo de dormência dos tubérculos.

$\mathrm{Na}$ camada de 0 a $10 \mathrm{~cm}$, todos os tratamentos testados promoveram aumento significativo no número de tubérculos mortos como observado nas quatro maiores doses de diclosulam $\left(100,150,200\right.$ e $\left.250 \mathrm{~g} \mathrm{ha}^{-1}\right)$, sendo maiores que nas duas doses de sulfentrazone e sua menor dose $\left(75 \mathrm{~g} \mathrm{ha}^{-1}\right)$. Percentualmente, observou-se que todas as doses de diclosulam proporcionaram incrementos no número de tubérculos mortos, da ordem de 57\%, 329\%, $414 \%, 214 \%$ e $300 \%$ respectivamente, e as duas doses de sulfentrazone ( 800 e $1.000 \mathrm{~g} \mathrm{ha}^{-1}$ ) em $114 \%$ e $29 \%$ respectivamente (Figura 3 ). Esses aumentos na mortalidade de tubérculos podem ser explicados pela condição térmica e hídrica presente no camalhão, que favoreceram a deterioração dos tubérculos, bem como a ação de microrganismos que causaram a conseqüente morte 
Tabela 4. Número de tubérculos germinados, dormentes e mortos no camalhão $\left(\mathrm{n}^{\circ} \mathrm{m}^{2}\right)$, aos 110 dias após a aplicação dos herbicidas, diclosulam e sulfentrazone em diferentes profundidades. Jaú (SP)

\begin{tabular}{|c|c|c|c|c|}
\hline \multirow[t]{2}{*}{ Tratamentos } & \multirow[t]{2}{*}{ Dose } & \multicolumn{3}{|c|}{ Profundidade 0 a $10 \mathrm{~cm}$} \\
\hline & & germinados & dormentes & mortos \\
\hline & $\mathrm{g} \mathrm{ha}^{-1}$ & \multicolumn{3}{|c|}{$\mathrm{n}^{\circ} \mathrm{m}^{-2}$} \\
\hline 1. Diclosulam & 75 & $47,8 \mathrm{~b}$ & $63,7 \mathrm{e}$ & 87,6 e \\
\hline 2. Diclosulam & 100 & 15,9 c & $135,4 \quad b$ & $183,1 \mathrm{c}$ \\
\hline 3. Diclosulam & 150 & 15,9 c & 71,7 ed & 286,6 a \\
\hline 4. Diclosulam & 200 & $15,9 \mathrm{c}$ & $87,6 \mathrm{~d}$ & $175,2 \mathrm{c}$ \\
\hline 5. Diclosulam & 250 & 0,0 e & 79,6 ed & $222,9 \mathrm{~b}$ \\
\hline 6. Sulfentrazone & 800 & $8,0 \mathrm{~d}$ & $119,4 \mathrm{bc}$ & $119,4 \mathrm{~d}$ \\
\hline 7. Sulfentrazone & 1.000 & $15,9 \mathrm{c}$ & $111,5 \mathrm{c}$ & $71,7 \mathrm{f}$ \\
\hline 8. Testemunha no mato & - & $63,7 \mathrm{a}$ & 302,6 a & $55,7 \mathrm{~g}$ \\
\hline F Bloco & & $0,82^{\mathrm{ns}}$ & $1,26^{\mathrm{ns}}$ & $0,95^{\mathrm{ns}}$ \\
\hline F Tratamento & & $351,15^{* *}$ & $420,53^{* *}$ & $539,52^{* *}$ \\
\hline CV (\%) & & 11,2 & 6,9 & 5,2 \\
\hline DMS & & 3,32 & 17,53 & 10,06 \\
\hline
\end{tabular}

\begin{tabular}{|c|c|c|c|c|}
\hline 1. Diclosulam & 75 & $63,7 \mathrm{a}$ & $103,5 \mathrm{ab}$ & $191,1 \mathrm{c}$ \\
\hline 2. Diclosulam & 100 & $8,0 \quad \mathrm{e}$ & $103,5 \mathrm{ab}$ & $262,7 \mathrm{~b}$ \\
\hline 3. Diclosulam & 150 & 8,0 e & $95,5 \mathrm{~b}$ & 310,5 a \\
\hline 4. Diclosulam & 200 & $23,9 \mathrm{~d}$ & 39,8 e & $47,8 \quad \mathrm{e}$ \\
\hline 5. Diclosulam & 250 & 31,9 c & 111,5 a & $87,6 \quad d$ \\
\hline 6. Sulfentrazone & 800 & $8,0 \quad \mathrm{e}$ & $55,7 \mathrm{~d}$ & $23,9 \mathrm{f}$ \\
\hline 7. Sulfentrazone & 1.000 & $8,0 \quad \mathrm{e}$ & $71,7 \quad \mathrm{c}$ & $87,6 \mathrm{~d}$ \\
\hline 8. Testemunha no mato & - & $39,8 \quad b$ & $79,6 \quad \mathrm{c}$ & $191,1 \mathrm{c}$ \\
\hline F Bloco & - & $0,33^{\mathrm{ns}}$ & $0,81^{\mathrm{ns}}$ & $0,24^{\mathrm{ns}}$ \\
\hline F Tratamento & - & $335,77^{* *}$ & $184,49^{* *}$ & $1415,2^{* *}$ \\
\hline CV $(\%)$ & - & 10,4 & 5 & 4,1 \\
\hline DMS & - & 5,15 & 8,63 & 12,77 \\
\hline
\end{tabular}

Adicionou-se aterbane a $0,05 \% \mathrm{v} / \mathrm{v}$ em todos os tratamentos químicos. ns = Não significativo

** = significativo ao nível de $1 \%$ de probabilidade pelo teste F.

Médias seguidas de mesma letra na coluna, não diferem estatisticamente entre si, pelo teste $t(P>0,05)$.

$\mathrm{CV}=$ Coeficiente de variação.

DMS = Diferença minima significativa

Na camada de 10 a $20 \mathrm{~cm}$ de profundidade, a quantidade de tubérculos mortos encontrados na testemunha foi superior ou semelhante em relação à maioria dos tratamentos químicos testados, com exceção das doses de 100 e $150 \mathrm{~g} \mathrm{ha}^{-1}$ de diclosulam. Assim, as maiores mortalidades em ambas as profundidades foram encontradas com a aplicação da dose de $150 \mathrm{~g} \mathrm{ha}^{-1}$ de diclosulam. Em termos percentuais observou-se que as doses de diclosulam de 100 e $150 \mathrm{~g} \mathrm{ha}^{-1}$ proporcionaram incrementos no número de tubérculos mortos, da ordem de 38 e $63 \%$, respectivamente. Enquanto as maiores doses (200 e $250 \mathrm{~g} \mathrm{ha}^{-1}$ ) condicionaram a reduções no número de tubérculos mortos correspondente a 75 e $54 \%$ e as doses de sulfentrazone (800 e $1.000 \mathrm{~g} \mathrm{ha}^{-1}$ ) em 88 e $54 \%$, respectivamente (Figura 4 ).

A reduzida quantidade de tubérculos mortos verificados nas doses de sulfentrazone pode estar relacionada à baixa atividade do herbicida nas condições do estudo; este fato pode ter ocorrido pela adsorção do herbicida ao solo, uma vez que o $\mathrm{pH}$ do solo $(4,9)$ estava abaixo do valor de $\mathrm{pKa}$ do herbicida sulfentrazone $(6,56)$, condições que favorecem a adsorção. Portanto, este herbicida proporciona forte dependência ao $\mathrm{pH}$ de carga variável que afeta sua ionização, atividade química e destino no solo (GREY et al., 2000). 


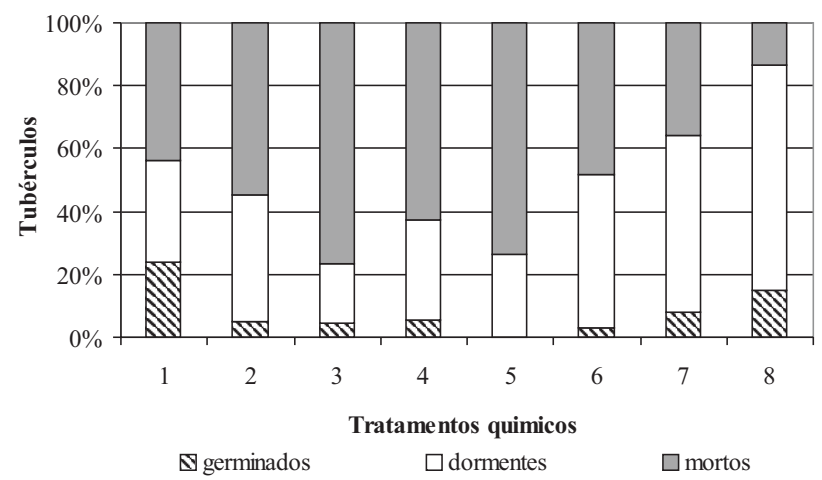

1. diclosulam 75; 2. diclosulam 100; 3. diclosulam 150; 4. diclosulam 200 5. diclosulam 250; 6. sulfentrazone 800; 7. sulfentrazone $1000 \mathrm{~g}$ ha-1

Figura 3. Porcentagem de tubérculos germinados, dormentes e mortos no camalhão de 0 a $10 \mathrm{~cm}$ de profundidade após tratamento com herbicidas e diferentes doses. Jaú (SP).

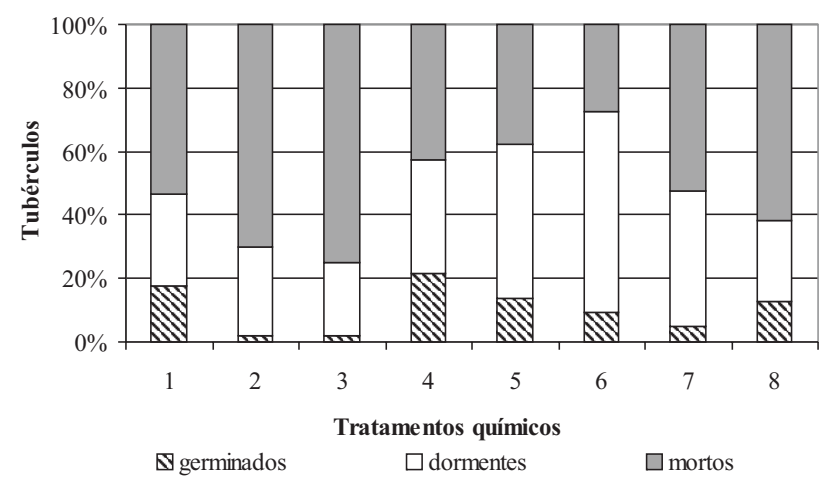

1. diclosulam 75; 2. diclosulam 100; 3. diclosulam 150; 4. diclosulam 200 5. diclosulam 250; 6. sulfentrazone 800; 7. sulfentrazone $1000 \mathrm{~g}$ ha-1

Figura 4. Porcentagem de tubérculos germinados, dormentes e mortos no camalhão de 10 a $20 \mathrm{~cm}$ de profundidade após tratamento com herbicidas e diferentes doses. Jaú (SP).

Nas maiores doses de diclosulam (200 e 250 $\left.\mathrm{g} \mathrm{ha}^{-1}\right)$, a redução no número de tubérculos mortos pode ser explicada pela maior indução de dormência verificada em relação aos demais tratamentos. Portanto, a hipótese de adsorção ao solo não se aplica para este herbicida, uma vez que o mesmo possui $\mathrm{pKa}$ $(4,09)$ semelhante ao $\mathrm{pH}$ do solo.

\section{CONCLUSÕES}

1. Os herbicidas sulfentrazone e diclosulam foram eficazes no controle de manifestações epígeas de tiririca e para o herbicida diclosulam foi dependente da dose utilizada.

2. A dose de $150 \mathrm{~g} \mathrm{ha}^{-1}$ de diclosulam propiciou alta mortalidade de tubérculos e a dose de $250 \mathrm{~g} \mathrm{ha}^{-1}$ induziu os tubérculos à dormência no sulco de plantio.

3. O herbicida sulfentrazone aplicado na dose $1.000 \mathrm{~g} \mathrm{ha}^{-1}$ no sulco de plantio incrementou a dormência dos tubérculos na camada mais profunda do solo.

4. A mortalidade de tubérculos foi menor quando aplicado o sulfentrazone independentemente das doses testadas, tanto no sulco de plantio como no camalhão.

5. A germinação de tubérculos provenientes do sulco de plantio foi mais intensa do que do camalhão, independente do tratamento testado.

\section{AGRADECIMENTOS}

À usina Diamante pela estrutura oferecida e cooperação dos funcionários na realização deste trabalho.

\section{REFERÊNCIAS}

BAILEY, W. A., WILCUT, J. W.; JORDAN, D. L., SWANN, C. W.; LANGSTON, V. B. Weed management in peanut (Arachis hypogaea) with diclosulam preemergence. Weed Technology, Champaign, v. 13, p. 450-456, 1999a.

BAILEY, W. A., WILCUT, J. W.; JORDAN, D. L., SWANN, C. W.; LANGSTON, V. B. Response of peanut (Arachis hypogaea) and selected weeds to diclosulam. Weed Technology, Champaign, v. 13, p. 771-776, 1999 b.

BARNES, J. W., OLIVER, L. R..; BARRENTINE, J. L. Potential of diclosulam (Strongarm) for weed control in soybeans. Proceedings of Southern Weed Science Society, Champaign, v. 51 p. 61-62, 1998.

CARNEIRO, P. A. M.; VIVIAN, R.; JAKELAITIS, A; REIS, M.R.; SILVA, A.A. Manejo químico de Cyperus rotundus na cultura da cana-de-açúcar. In: CONGRESSO BRASILEIRO DE CIÊNCIA DAS PLANTAS DANINHAS, 25., Brasília, 2006. Resumos... Brasilia: SBCPD, 2006. p.338.

DURIGAN, J.C., TIMOSSI, P.C. e CORREIA, N.M. Manejo integrado da tiririca na produtividade de cana-de-açúcar. Planta Daninha, Viçosa, v. 24, p. 77-81, 2006.

DURIGAN, J.C.; TIMOSSI, P.C.; LEITE, G.J. Controle químico da tiririca (Cyperus rotundus), com e sem cobertura do solo pela palha de cana-de-açúcar. Planta Daninha, Viçosa, v.22, p.127-135, 2004. 
DURIGAN, J.C.; CORREIA, N.M.; TIMOSSI, P.C. Estádios de desenvolvimento e vias de contato e absorção dos herbicidas na inviabilização de tubérculos de Cyperus rotundus. Planta Daninha, Viçosa, v. 23, p. 621-626, 2005.

FRANCO, D. S.; ROZANSKI, A.; BLANCO, F. M. G.; ALMEIDA, S.D.B.; MATALLO, M. B. Flora de Cyperus rotundus na cultura de cana-de-açúcar orgânica colhida mecanicamente crua. In: CONGRESSO BRASILEIRO DE CIÊNCIA DAS PLANTAS DANINHAS, 25., 2006. Brasília. Resumos... Brasilia: SBCPD, 2006. p. 491.

GREY, T. L.; WALKER, R. H.; WEHTJE, G. R.; ADAMS JÚNIOR, J.; DAYAN, F. E.; WEETE, J. D.; HANCOCK, H. G.; KWON, O. Behavior of sulfentrazone in ionic exchange resins, electrophoresis gels, and cation-saturated soils. Weed Science, Champaign, v. 48, p. 239-247, 2000.

HAMMERTON, J.L. Experiments with Cyperus rotundus L. III Seasonal variations in growth. Weed Research, Oxford, v.15, p.339-348, 1975.

HOLM, L.G.; P LUCKETT, D.L.; PANCHO, J.W.; HERBERGER, J. P. The world's worst weeds: distribution and biology. Honolulu:University Press Hawaii, 1977. 609p.

KISSMANN, K. G.; GROTH, D. Plantas infestantes e nocivas. 2.ed. São Paulo: BASF, 1997. 825 p.

LANGBECK, F.M.; NOVO, M.C.S.S.; LAGO, A.A.; DEUBER, R. Viabilidade de tubérculos de Cyperus rotundus L. tratados com sulfentrazone. Arquivos do Instituto Biológico, São Paulo, v.71, (supl.), p.372-375, 2004. (Resumo expandido, 196)

LORENZI, H. Plantas daninhas do Brasil: terrestres, aquáticas, parasitas e tóxicas. 3. ed. Nova Odessa: Instituto Plantarum, 2000. 640 p.

MELLO, S. C. M. de; TEIXEIRA, E. A.; NETO, C. R. B. Fungos e seus metabólicos no controle de tiririca. Brasília: Embrapa Recursos Genéticos e Biotecnologia, 2003. 55 p. ( Embrapa Recursos Genéticos e Biotecnologia, 104)

MILES, J. E.; NISHIMOTO, R. K.; KAWABATA, O. Diurnally alternating temperatures stimulates sprouting of purple nutsedge (Cyperus rotundus) tubers. Weed Science, Champaign, v. 44, p. 122-125, 1996.

NEGRISOLI, E. VELINI, E. D.; COSTA, A.G.F.; ROSSI, C.V.S.; CORREA, T. M.; CAVENAGHI, A. L. Avaliação da eficácia de herbicidas no controle de tiririca (Cyperus rotundus). In: CONGRESSO BRASILEIRO DE CIÊNCIA DAS PLANTAS DANINHAS, 24, 2004, São Pedro. Resumos... São Paulo: SBCPD, 2004. p. 221.

NOVO, M. C. S. S. Efeito da palha de cana de açúcar e do tamanho de tubérculos no desenvolvimento da tiririca (Cyperus rotundus L.). Piracicaba, 2004. 107p. Tese (Doutorado em Agronomia), ESALQ, Piracicaba, 2004.

OKOLI, C.A.N.; SHILLING, D.G.;SMITH, R.L.; BEWICK, T.A. Genetic diversity in purple nutsedge (Cyperus rotundus L.) and yellow nutsedge (C. esculentus L.). Biological Control, Orlando, v. 8, p. 111-118, 1997.
PEREIRA, W. Estudos de variabilidade morfo-fisiológica, diversidade genética e susceptibilidade a patógenos de acessos de tiririca de diferentes regiões e suas influências no controle biológico da planta daninha. Brasília: EMBRAPA-CNPH, 1998. $135 \mathrm{p}$.

SILVA, J.R.V., COSTA, N.V. e MARTINS, D. Efeito da palhada de cultivares de cana-de-açúcar na emergência de Cyperus rotundus. Planta Daninha, Viçosa, v.21, p.375-380, 2003.

STOLLER, E. W.; SWEET, R. D. Biology and cycle of purple and yellow nutsedge (C. rotundus and $C$. esculentus). Weed Technology, Champaign, v. 1, p. 66-73, 1987.

TAVARES, S.; HORA, R. C. da. Diagnóstico das principais culturas do pólo regional de desenvolvimento e tecnologia dos agronegócios do extremo oeste, - 2005 Disponível em: $<\mathrm{ht} \mathrm{tp}$ : / / w w w . a p taregional.s p.gov.b r / artigo.php?id_artigo=263> Acesso em 05/06/2006.

TERRA, M. A. Seletividade de Diclosulam, trifloxisulforonsodium e ametryne a variedades de cana-de-açúcar. Botucatu. 2003. 60f. Dissertação (Mestrado em Agricultura) Universidade Estadual Paulista, 2003.

WEHTJE, G. R.; WALKER, R. H.; GREY, T. L. HANCOCK, H. $\mathrm{G}$. Response of purple (Cyperus rotundus) and yellow nutsedge (C. esculentus) to selective placement of sulfentrazone. Weed Science, Champaign, v. 45, p. 382-387, 1997.

WERLANG, R. G.; SILVA, A. A.; REIS, M. R. dos; JAKELAITS, A. Manejo de plantas daninhas na cana-de-açúcar plantio de ano. In: CONGRESSO BRASILEIRO DE CIÊNCIA DAS PLANTAS DANINHAS, 24., 2004, São Pedro. Resumos...São Pedro: SBCPD, 2004. p.163.

WILLS, G. D. Description of purple and yellow nutsedge (Cyperus rotundus and C. esculentus). Weed Technology, Champaign, v. 1, p. 2-9, 1987. 